\title{
Teachers' academic expectations and psychological distress among adolescents in private secondary schools in Nairobi County, Kenya
}

\author{
Angelline Kalondu Kiamba, Dr. Joel Kiambi Muriithi, Dr. Florence Githuthu \\ Department of Counseling Psychology, Faculty of Arts and Social Science, The Catholic University of Eastern Africa, Kenya
}

\begin{abstract}
The increase in levels of psychological distress among adolescents due to different factors are alarming, however since most adolescents are attending school. This study worked to establish the relationship between academic expectations and psychological distress experienced by adolescents in private secondary schools in Nairobi County Kenya. Specific objective was to determine if teachers' academic expectations contribute to psychological distress among adolescents in private secondary schools in Nairobi County. Ecological Systems Theory founded by Urie Bronfen brenner in 1979 and General Strain Theory founded by Robert Agnew in 1992 anchored the study. A convergent parallel mixed method design was adopted, which involved descriptive survey and phenomenological methods for quantitative and qualitative enquiries respectively. A total sample of 387 respondents from 28 private secondary schools was used which included 380 students and 7 guidance and counseling teachers sampled through simple random, proportionate, and purposive sampling techniques. Data was collected through questionnaires and semi-structured interviews. Quantitative data was analyzed through descriptive and inferential analysis specifically chi-square and correlation using SPSS version 22 .The qualitative data from guidance and counseling teachers was analyzed using content analysis. The results were then presented using tables for quantitative data, and data collected through semi-structured interviews was presented through quotes and narrative descriptions. The findings showed that adolescents experienced academic expectations from teachers. Teachers' academic expectation was significantly influenced by age and mothers' educational level. In relation to psychological distress, teachers' academic expectations had a weak positive relationship with anxiety, stress and depression symptoms.
\end{abstract}

Key Words: Academic expectation, psychological distress

\section{INTRODUCTION}

A dolescence is also a crucial and important stage in human development. However, in our world currently this age group which ranges between 13-19 years, seems to be subjected to a number of challenges that expose them to low psychological wellbeing. According to world health organization mental health issues account for 16 percent of the global burden of injury and disease in individuals aged between 10-19 years. Depression is one of the leading causes of illness and disability with suicide being the third cause of death among adolescents globally (WHO 2020). This leaves many to wonder what could be the contributing factors to these alarming statistics. Most of the adolescents are at their school going period where they spend most of their hours in a day. Could it be that these challenges they face that lead to low wellbeing are academic related?

The organization for economic co-operation and development (OECD) conducted a survey that involved 72 countries with 540,000 students as respondents aged 15-16 years. This study revealed that 66 percent of the students reported feeling stressed about poor grades and 59 percent expressed that they often worry that taking a test will be difficult. 37 percent felt much tensed when studying and 55 percent feel very anxious about-facing exams even when they were well prepared. The above study also reports that the secondary school students who self -report higher levels of academic -related stress also report low well-being (OECD 2017), which means the academic challenges the adolescents are exposed to in our current world can be associated with the mental health challenges they face. The key responsibility lies with the school leaders and family members in not becoming perpetuators of this psychological distress but rather creating a safe and nurturing environment in supporting the social and emotional well-being of the adolescents as they negotiate the challenges that are brought by strain for academic attainments.

In recent years' mental health issues for Students, especially in terms of academic stress and its impact has become a serious issue among researchers and policymakers because of increasing incidence of suicides among students across the globe. According to a study conducted in India by Deb, Strodi \& Sun (2015), 63.5 percent of the higher secondary students in Kolkata experience academic stress. Parental pressure for better academic performance was found to be mostly responsible for academic stress as reported by 66.0 percent of the students. This study showed that there are instances of mental health problems among secondary school students and senior high school students because the students had been pushed by parents and teachers to perform well in art and music lessons, hence students cannot cope with the demands anymore and emotionally collapse when the stress is high. The overall unemployment situation in India and other parts of the world has also provoked parents to put pressure on their children for better performance. Some of the parents wish to fulfil their unfulfilled dreams through their children. These expectations are likely to leave the adolescents exposed to so 
many demands and strains most of which may be too much for them to handle.

It has been established that high stakes examinations are constantly becoming a significant source of stress and worry for students in secondary schools. The question would be why are the students not able to face their examinations calmly? Could it be there is high expectation from others around them and even themselves?, which could answer why adolescents that are in schools are exposed or facing psychological distress. Banks \& Smyth (2015), in their study conducted in Ireland shows that stress among students is not only influenced by their individual-level factors but that, stress also results from certain other aspects of the schooling process, particularly the quality of student-teacher interaction. Stress is also influenced by the program a student chooses at upper level of learning and the extent to which the learner is facilitated in their choice of subjects. This study brings some enlightenment that there are so many intertwined environmental factors that are likely to exposé the adolescent to psychological distress during their schooling period.

Higher education in the developing world of which Africa is part, is becoming one of the most valued experiences today. Education is considered to be the major instrument for promoting socio-economic, political and cultural development in Africa. This has attracted a fast-growing rate of opening of both public and private based secondary schools and universities (National Council for Higher Education, 2018). The most affected persons in the whole scenario are the students because they have to live up to the expectations and the demands of the modern society. The demands are not only from the society but for the students themselves because the desire to live up to the standards that are being set by those before them hence subjecting themselves to extreme pressures that leave them psychologically drained.

Nalugya et al., (2016) conducted a study on prevalence and factors associated with depression symptoms among schoolgoing adolescents in central Uganda and the results were alarming, 21 percent of the participants had significant depression symptoms, with 11 percent meeting the criteria for major depression, 3.1 percent reported current suicidal ideation. These depression symptoms were associated with single-sex schools, alcohol use and loss of close family members. This study makes it clear again that adolescents in schools are struggling with mental health issues and something needs to be done to establish clearly the root causes as to why school going adolescents are facing these challenges and what measures could be put in place to eradicate the same or minimize the occurrence.

The issue of psychological distress among students seems to be greatly affecting many adolescents in our region. A study conducted on suicidal ideation among school-attending adolescents in Dar es Salaam, Tanzania by Dunlavy, Aquah \& Wilson (2015), in which 2,176 students aged 11-16 years participated revealed that 7 percent of the participants had thought about taking their lives of which 6.3 percent were having a clear plan on how to carry out the attempt. The majority of them amounting to 50 percent were female. In the multivariate analysis of the study the adolescents who reported suicidal intent had clear depression symptoms and had previously used illicit substances. The study was able to establish that social and familial support are some of the factors that impacted suicidal ideation. However, the researcher didn't bring out clearly how these factors promoted mental health issues and how they are specific to the school going adolescents, which is an aspect that this study worked address.

According to Luketero \& Wambui (2020), who conducted a study on the factors influencing students' academic performance in Kenyan Certificate of Secondary Education in Kirinyaga Central Sub- County, some factors affecting students' performance are the peers influencing each other on drug and substance abuse, premarital indecency, dressing indecently, laziness and other activities most of which could tell us that there are psychological health issues that the students may be struggling with. In order to understand the depth of mental health issues among adolescents in secondary schools in Kenya, it is good to look at who seeks child and adolescent mental health care in this country. Wanjiku, Omighodun, Bella \& Adodokun (2017), did a cross sectional descriptive study on clinic profile at a tertiary referral facility in Kenya and established that most referrals to the clinic were coming from medical practitioners and teachers, which made it clear that a majority of Kenyan adolescents at one time or another are likely to suffer mental health challenges during their schooling period. Again, education is a basic human right and every student should be assisted to go through school period smoothly. In Kenya there are few programs that have been put in place to address mental health for students because health budget is wanting, hence the need to involve community, parents, teachers and students themselves in dealing with this challenge (Muthoni 2019). For them to fully participate in this endeavor it would be wiser if they were aware how they may be perpetuators of the same problem. Therefore, the current study aimed to bring this awareness by investigating how the academic expectations contribute to mental health issues among adolescents in secondary schools.

Nairobi County in Kenya where the study was conducted, being a cosmopolitan city and also highly populated, has many public and private schools. According to Shiundu (2019), private schools in Kenya, especially in Nairobi are soaring in popularity, even poor families who struggle to get school fee are taking their children to private school instead of taking them to free public schools. This is due to the fact that private schools are known for quality education. This demand for private schools in Nairobi, indeed is likely to lead to more academic expectations due to high competition. To live up to the standards of the different levels of category of these schools' high performance from the students is expected. On the other hand, adolescents who make up the population of students in secondary schools, are entangled in these demands 
for high academic performance in the city which may expose them to mental health challenges in dealing with this strain. A study conducted in Nairobi County, Kenya on depression and anxiety symptoms, social support, and demographic factors among Kenya high schools' students, revealed high levels of depression symptoms of about 45.90 percent above clinical cutoff, anxiety symptoms were 37.99 percent. Older and female adolescents showed high levels of anxiety and depression symptoms (Osborn, Venturo, Wasil, Schleider \& Weisz 2019). This study gives a clear evidence of the prevalence of psychological distress among adolescents in secondary schools in Nairobi county Kenya. Therefore, the current study went further to establish whether the anxiety and depressive symptoms that these adolescents experience are related to academic expectations that they are exposed to.

Based on different studies that have been discussed, it shows clearly that school going adolescents are subjected to a lot of pressure from different sides and it is evident that they are struggling with psychological issues. Most of the research studies have established the presence of mental health issues among school going adolescents and have gone further to seek possible interventions for the same. Though a number of studies have looked at the factors leading to this problem among the adolescents, there may be no known study that has looked at academic expectations as a key factor that could be influencing this problem except a study conducted in India by Deb., et al (2015) which revealed that there was a relationship between academic expectations from parents and mental health issues among adolescents. On the whole, there are large gaps in data on the burden of mental health challenges and the contributing factors in low and middle-income countries. Kenya which falls under this bracket provides little data on the burden of mental illness and root causes especially among the adolescents (APHRC 2019). Therefore, the current study worked to establish whether there is a relationship between academic expectations and psychological distress that is experienced by adolescents with special concentration on private secondary school in Nairobi county Kenya, since there may be no known study of this nature which has been done in this area.

\section{METHODS}

\section{Research Design}

This study used convergent parallel mixed method design. The design involves collection of both qualitative and quantitative data concurrently, then followed by analysis of both data separately and merging of the results during interpretation (Creswell 2014). Descriptive survey and phenomenological design for quantitative and qualitative respectively aided this enquiry. Convergent parallel mixed method was found appropriate for this study since it provides a comprehensive analysis of the problem under study by looking at the relationship between both qualitative and quantitative data and later merging both data to draw deeper meaning. The method was also appropriate for academic research due to limited time and resources.

Descriptive survey works to establish the range and distribution of some social characteristics. This was necessary for this study because it gives a clear explanation of the characteristics of the population or situation under study. In this study the focus was to investigate the sources of academic expectations and how they affect the adolescents psychologically in private secondary schools in Nairobi County. A descriptive survey allowed the researcher to describe behavior as it occurs in the environment. This was done through self-rated questionnaires which allowed for anonymous peek inside the thought processes of large numbers of people simultaneously thus creating an opportunity to describe what is not outwardly observable (Shields \& Rangarajan 2013).

Phenomenological research design involved in-depth description by the researcher of the lived experiences of the individuals about a particular phenomenon as reported by the participants (Creswell 2014). This data was collected through semi-structured interview guide for the guidance and counseling teachers

\section{Target Population}

According to Majid (2018), target population is the group of interest which the researcher intends to study and where the sample will be drawn from. It should have some observable characteristics that meet the eligibility criteria that the researcher has set to achieve his/her objectives. The target population for this study was all students and all guidance and counseling teachers in private secondary schools in Nairobi County, Kenya. The students in private secondary schools were targeted because they at the adolescence stage and also there is higher chances of more academic expectation in private schools than public schools. The guidance and counseling teachers because they are the ones who handle psychological issues in the schools and keep record of the same.

According to Republic of Kenya Ministry of Education (2019), there are 283 private secondary schools in Nairobi County with total enrolment of 33,381 students.

\section{Inclusion/Exclusion Criteria}

The following was the criteria utilized to select the needed respondents, first, one had to be a secondary school students or guidance and counseling teacher in secondary school, secondly, had to be from a private school, third, the private school had to be in Nairobi county, fourth, one must have been sampled and lastly, one must have given informed consent for participation.

\section{Subject Selection}

It is difficult to collect data from all cases especially where the target population is huge. Thus, there is need to select a sample, since the researchers do not have time or resources to 
collect and analyze data from the entire population (Taherdoost, 2016). For this study the researcher employed probability and non-probability sampling procedures to select the respondents needed. In probability sampling, each private school and individual student of the target population had equal chance of being selected which did not happen in nonprobability sampling where the researcher purposively went to the individual guidance and counseling teachers that were available and were likely to give the desired information needed in the study. Form three students mainly took part in this study because they were more likely to be settled in the school and were giving full attention to all aspects of their academic performance as compared to form ones and twos who were still adjusting to new school environment, and on the other hand form fours were mainly concerned with their forth coming national examinations.

According to Kothari (2013), a sample of 10 percent to 30 percent is necessary for descriptive studies. Since there were 283 private schools in Nairobi County, a sample of 28 schools was used which was arrived at by calculating 10 percent of the total population of schools. The researcher used simple random technique to sample the schools by writing the names of the 283 schools in small pieces of paper, mix them in a container and then randomly pick 28 schools. Krejcie and Morgan (1970) formula was used to determine the sample size of the students in private secondary schools in Nairobi County that is required for the study. Krejcie and Morgan formula is as follows: -

$S=X^{2} N P(1-P) / d^{2}(N-1)+X^{2} P(1-P)$

Where:

$S=$ required sample size

$X^{2}=$ the table value of chi-square for 1 degree of freedom at the desired confidence level (3.841)

$N=$ the population size

$P=$ the population proportion (assumed to be 0.50 since this would provide the maximum sample size

$d=$ the degree of accuracy expressed as a proportion (.05)

The target population for students in private secondary schools in Nairobi is 33,381 .

Therefore: -

$S=3.841(33381)(0.5)(0.5) / 0.05^{2}(33381-1)+3.841(0.5)$

$(0.5)$

$$
\begin{aligned}
& =32054.1052 / 84.41025 \\
& =379.741858 \\
& =380 \text { Students. }
\end{aligned}
$$

The students were sampled through proportionate sampling, therefore the sample of students from each of the sampled schools depended on the population size of the students in each school. Seven guidance and counseling teachers were purposively sampled for the study.

\section{Research Instrument}

A research instrument is the researcher's measurement tool, which is designed to obtain data from the research subjects on a particular topic that is of interest to the researcher (Des Moines University library, 2020). The choice of a research instrument depends on the topic under study and the type of data that the researcher intends to collect. The current study used standard instruments which were Educational Stress Scale for Adolescents (ESSA) and Depression, Anxiety, Stress Scale- 21 (DASS-21), to collect quantitative data from students and semi-structured interviews were used to collect qualitative data from guidance and counseling teachers.

\section{RESULTS}

Prevalence of Teachers' Academic Expectations among Adolescents in Private Secondary Schools in Nairobi County

Descriptive frequencies was used to investigate the mean and Standard deviation of the teachers' academic expectations in relation to demographic features of the adolescents on a scale of strongly disagree ( $\mathrm{M}=$ upto 5.5$)$, Disagree $(\mathrm{M}=5.5-11.5)$, Neutral $(\mathrm{M}=11.5$ - 17.5), Agree $(\mathrm{M}=17.5-23.5)$ and Strongly Agree $(\mathrm{M}=23.5$ and above $)$. The results are presented in table 4.10 .

\begin{tabular}{|c|c|c|c|}
\hline \multicolumn{2}{|c|}{ Demographic Factors } & Mean (M) & SD \\
\hline \multirow{5}{*}{$\begin{array}{c}\text { Age of } \\
\text { Respondents }\end{array}$} & 16 & 24.92 & 3.199 \\
\hline & 17 & 23.64 & 3.482 \\
\hline & 18 & 23.96 & 2.913 \\
\hline & 19 & 23.51 & 2.747 \\
\hline & 20 & 22.67 & 2.887 \\
\hline \multirow{2}{*}{ Gender } & Male & 23.66 & 3.285 \\
\hline & Female & 23. & 3.166 \\
\hline \multirow{4}{*}{$\begin{array}{l}\text { Father's } \\
\text { Educational } \\
\text { Level }\end{array}$} & Primary & 22.91 & 2.536 \\
\hline & Secondary & 22.27 & 3.131 \\
\hline & College & 23.79 & 3.038 \\
\hline & University & 23.87 & 3.534 \\
\hline \multirow{4}{*}{$\begin{array}{l}\text { Mother's } \\
\text { Education } \\
\text { Level }\end{array}$} & Primary & 22.75 & 2.926 \\
\hline & Secondary & 24.54 & 2.902 \\
\hline & College & 24.04 & 7.534 \\
\hline & University & 23.68 & 7.836 \\
\hline
\end{tabular}

Table 1 : The Mean of Demographic Features in Relation to Teachers' Academic Expectations

As indicated in table 1, the respondents aged 16, 17,18 and 19 years strongly agreed that there were academic expectations from teachers with the highest mean of $(\mathrm{M}=24.92 \& \mathrm{SD}=$ 3.199) for the adolescents aged 16. The ages $17(\mathrm{M}=23.64$, $\mathrm{SD}=3.482), 18(\mathrm{M}=23.96 \& \mathrm{SD}=2.913), 19(\mathrm{M}=23.51 \&$ 
$\mathrm{SD}=2.747$ ) mean was fairly distributed in strong agreement. While those aged 20 years agreeing to the same with a mean of 22.67 and SD of 2.887. In relation to gender the mean was fairly distributed with both male and female respondents strongly agreeing to the fact that there was academic expectation from their teachers. Therefore the age and gender seem to have no influence on the way the teachers expected their student adolescents to perform.

In relation to their parents' educational level, the respondents whose their fathers had attain higher education, that is college and university strongly agreed to the fact that there were academic expectations from the teachers, with a mean of 23.79, $\mathrm{SD}=3.038$ and $23.87, \mathrm{SD}=3.534$ respectively, while those whose fathers had attained primary and secondary followed slightly behind agreeing to the same with a mean of 22.91, $\mathrm{SD}=2.536$ and $22.27, \mathrm{SD}=3.131$ respectively. Almost the same trend was noticed in relation to mothers educational level, those whose their mothers had attained secondary, college and university reported to the fact that, they strongly agreed that teachers had academic expectations of them. The ones whose mothers had attained primary education followed slightly behind the rest agreed to the same fact too $(M=22.75 \& S D 2.926)$. The mean seems not to give a clear indication whether Parents' educational level had any influence on the way the teachers expected the adolescents to perform academically according demographics descriptively. Therefore the researcher carried out a Chi-square test.

\section{Significance of Demographic Features in Relation to Teachers' Academic Expectations}

In this section a Chi square test was used to investigate if demographics of the respondents in terms of age, gender and educational level of the parents had a significant influence on the teachers' academic expectations to the adolescents they teach. The examination followed a principle that if $\rho=<\alpha$ (0.05), then the demographic features in question has significant influence on teachers' academic expectations of the adolescents also, if $\alpha=0.001$, it indicates that the significance is very high; and if $\rho=\geq \alpha(0.05)$, then the demographic features in question have no significance influence on teachers' academic expectations of the adolescents.

Table 2: Significance of Teachers' Academic Expectations as Distributed by Demographics

\begin{tabular}{|c|c|c|}
\hline Demographic feature & $X^{2}$ & $p$ \\
\hline $\begin{array}{c}\text { Age of the } \\
\text { respondents }\end{array}$ & 15.622 & 0.048 \\
\hline $\begin{array}{c}\text { Gender of the } \\
\text { respondents }\end{array}$ & 1.494 & 0.474 \\
\hline $\begin{array}{c}\text { Educational level of } \\
\text { the fathers' }\end{array}$ & 11.894 & 0.064 \\
\hline $\begin{array}{c}\text { Educational level of } \\
\text { the Mothers' }\end{array}$ & 20.894 & 0.002 \\
\hline
\end{tabular}

The results for age in Table 2, with teachers' academic expectations $\left(X^{2}=15.622 \& \rho=0.048\right)$ shows that age of the adolescent had significant influence on teachers' academic expectations of them. On the other hand the gender of the adolescents had a $p$ value of 0.474 which is greater than alpha $(\alpha=0.05)$, indicating that gender had no significant influence on teachers' academic expectations of the adolescents.

Interestingly the fathers educational level had no significant influence on the teachers' academic expectations of the adolescents but the mothers educational level had significant influence on the teachers' academic expectations of the adolescents they taught, since the values of the fathers' educational level $\left(X^{2}=11.894 \& p=0.064\right.$ and mothers' educational level $\left(X^{2}=20.894 \& p=0.002\right)$, accounted to that. These findings could be explained with the fact that in Kenyan society the female parent seem to be more concerned and making a follow up of the academic performance of the adolescents while is school. They are more in contact with the teachers of their children and do more visit to the schools that the fathers of the adolescents.

Correlation of Teacher's Academic Expectations and Psychological Distress of Adolescents

Table 3: Pearson Correlation coefficient of Teachers' Academic Expectations to Psychological Distress

\begin{tabular}{|c|c|c|c|c|c|}
\hline \multicolumn{2}{|c|}{} & $\begin{array}{c}\text { Teachers'acade } \\
\text { mic expectations }\end{array}$ & $\begin{array}{c}\text { Anxiet } \\
\mathrm{y}\end{array}$ & $\begin{array}{c}\text { Stres } \\
\mathrm{s}\end{array}$ & $\begin{array}{c}\text { Depressio } \\
\mathrm{n}\end{array}$ \\
\hline \multirow{2}{*}{$\begin{array}{c}\text { Teachers' } \\
\text { academic } \\
\text { expectatio } \\
\mathrm{ns}\end{array}$} & $\begin{array}{c}\text { Pearson } \\
\text { Correlatio } \\
\mathrm{n}\end{array}$ & 1 & .236 & .337 & .189 \\
\cline { 2 - 6 } & $\begin{array}{c}\text { Sig (2- } \\
\text { tailed) }\end{array}$ & .000 & .000 & .000 & .000 \\
\cline { 2 - 6 } & $\mathrm{N}$ & 380 & 380 & 380 & 380 \\
\hline
\end{tabular}

From the table above the teachers' academic expectation had weak positive relationship with anxiety, depression and stress symptoms. This positive relationship is also supported by four guidance and counseling teachers who took part in the interviews. They reported that teachers expected their students to perform in a certain way which pressured students to perform. Counselor 3, in particular reported,

Different subject teachers and even the school at large set targets that each student is expected to achieve at the end of the term or year. This keeps the students to their toes as they work to meet those targets and if they don't meet them they are summoned after the examinations to explain.

A study conducted in Ireland by Banks \& Smyth (2015), also supports the findings of the current study, it reported that Irish adolescents students were experiencing stress due to the academic interaction that they had with their teachers.

\section{DISCUSSION}

Studies have been conducted on role of teachers in academic distress of students in various parts of the world with varying results. Academic stress among Indian students has been an issue of great concern due to high competition of academic performance in Asian countries. A descriptive survey was 
done in Tamil Nadu, India by Venkatachalam \& Chellamuthu (2019), with the aim of identifying sources of academic stress among higher secondary school student. The findings reveal that the academic environment was the major source of academic stress rather than personal environment. The top five sources that were linked to academic stress were; parental expectations represented by 96 percent of the respondents, fear of failing the examinations (96 percent), comparisons with other students (89.9 percent), competition for grades (89.4 percent), and doing too many tests ( 74.7 percent). This informed the researcher in working to establish the sources of academic expectations among school going adolescents. At the same time the findings of the current study concur with this study in agreeing to the fact that there was academic expectations from teachers among adolescents in private secondary schools in Nairobi County.

Apart from teachers, there could also be an environmental or cultural source of academic expectation for adolescents in schools. For example, students/children coming from a particular culture or a particular socioeconomic background are expected to perform better than others. An Ex post facto study conducted in Chile by Canales \& Webb (2018), on educational achievement of indigenous students in Chile, school composition and peer effects; brought out that school socioeconomic background and indigenous status of the students influenced their academic achievement. The study involved a review of national test score data and an administering of questionnaires to students, teachers and parents. Analysis was conducted through linear model and random intercept model. Therefore, it is clear from the study that certain students, due to their background, are expected to perform in a certain way, hence exposing them to some kind of pressure to perform.

Teachers are important persons in the life of any student, so they are bound to influence the academic performance of all students depending on how they teach and the goals they set for their students. These expectations not only influence the students but the teachers themselves. A study was conducted in Ethiopian secondary schools on teachers' expectations of students' achievements as a predictor of motivation to teach. The study employed concurrent triangulation mixed method research design. Data was collected through questionnaires and focus group discussion. The respondents were 368 secondary school teachers and data was analyzed through descriptive statistics, t-tests, regression and Cohen tests. The results revealed that there was a relationship between the level teachers' student expectations and their motivation to teach. These expectations further affected students' academic behaviors in school and academic performance (Mulisa \&Kassahun 2019). This study brings out clearly that teachers indeed have academic expectation towards their students in Ethiopia. The current study worked and established that there was also academic expectations from teachers in private secondary schools in Nairobi County Kenya, and the teachers academic expectations had a weak positive relationship with the psychological distress that the adolescents experience.

\section{CONCLUSION}

The adolescents in private secondary schools in Nairobi County strongly agreed that teachers had academic expectations of them. Teachers' academic expectations were strongly influenced by the adolescent's mother's educational level, but not by age, gender, or the adolescent's father's educational level. Academic expectations of teachers, on the other hand, had a weak positive connection with anxiety, stress, and depression symptoms. The researcher recommended that teachers and other stakeholders in private secondary schools must collaborate to ensure that adolescents in private secondary schools are not exposed to unhealthy academic expectations.

\section{REFERENCES}

[1] African Population and Health Research Center (2019). Adolescents' mental health in Kenya: Where is the data? Retrieved from https://aphrc.org/blogarticle/adolescent-mentalhealth-in-kenya-where-is-the-data/

[2] Agnew,R.(1992). Foundation for a General Strain Theory of Crime and Delinquency, Criminology, 30(1),47-87

[3] Banks,J., \& Smyth,E.(2015). 'Your Whole life depends on it': Academic Stress and High-stakes testing in Ireland. Journal of Youth Studies 18(5),598-616,2015

[4] Bronfenbrenner,U.(1979). The ecology of human development: Experiments by nature and design.Cambridge,MA: Harvard University Press.

[5] Canales,A.\& Webb,A.(2018). Educational achievement of indigenous students in Chile: School composition and peer effects. Comparative Education Review 62(2):000000.https://doi.org/10.1086/696957

[6] Creswell,J.W.(2014). Research designs:Qualitative,quantitative and mixed methods approaches $\left(4^{\text {th }}\right)$ edition. California: Sage Publications, Inc.

[7] Deb,S., Strodi,E., \& Sun,J. (2015). Academic stress, parental pressure, anxiety and mental health among Indian high school students. International Journal of Psychology and Behavioral Sciences, 5,26-34. https://doi.org/10.5923/j.ijpbs.2015050.04

[8] Des moines university library (2020). What is a research instrument? Cumulative index for nursing and allied health literature.

http://support.epnet.com/knowledge_base/detail.php?id=3099

[9] Dunlavy, A.C., Aquah.E.O., \& Wilson, M.L. (2015). Suicidal ideation among school -attending adolescents in Dar es Salaam, Tanzania- Tanzania Journal of Health Research 17(1),2015

[10] Kothari,C.R. (2013). Research methodology: Methods and techniques, $2^{\text {nd }}$ edition. New Delhi: Gupta KK.

[11] Krejcie,R.V. \& Morgan,D.W. (1970). Determining sample size for research activities. Educational and psychological measurement 1970,30,607-610. Retrieved from https://home.kku.ac.th/sompong/guest_speaker/krejcieandmrgan_a rticle.pdf

[12] Luketero,S.W., \& Wambui,E.K.(2020). The Factors influencing Students' Academic performance in Kenya Certificate of Secondary Education in Kirinyaga Central sub-County Kenya. International Journal for Innovation Education and Research 7(4):1-11. Vol 17. Iss4.1143. https://doi.org/10.31686/ijier

[13] Majid,U.,(2018). Research Fundamentals: Study design, Population, and sample size. URNCST Journal: Vol 2,issue1. DOL:https://doi.org/1026685/urncst.16

[14] Mulisa,F. \& Kassahum,S.M. (2019). Teachers' expectation of students' achievement as a predictor of motivation to teach in Ethiopian secondary schools: Implication of quality education. Retrieved

https://www.researchgate.net/publication/340829229 
[15] Muthoni,C.K. (2019). Mental health and education in Kenya: Addressing mental health problem through schools. IOSR, Journal of Humanities and Social Science. vol 24, issue 3, Ser.1(march.2019)40-43; $\quad$ e-ISSN:22790837.www.iosrjournals.org

[16] Nalugya,J.S., Zari,G.R., Ovuga,E., Kiwuwa,S.M., Musisi,S., \& Nakimuli,E.M. (2016).Prevalence and factors associated with depression symptoms among School-going Adolescents in Central Uganda. Child and Adolescent Psychiatry and Mental Health Journal: Vol:10 ,39pages. BioMed Central publisher.

[17] National Council for Higher Education. (2018). The State of higher Education and training in Uganda 2015/16: A report on higher Education Delivery and Institutions. Retrieved 5,2020, from http://www.unche.or.ug/publications/the-state-of-highereducation-and-training-in-uganda.html

[18] Obsborn,T.O., Venturo,K.C.,Wasil,A., Schleider,J.L., \& Weisz,J. (2019). Depression and Anxiety symptoms, Social support and Demographic factors among Kenyan high School Students. Journal of Child and Family studies 29(5), 1432-1443,2020

[19] Organization for Economic Co-operation and Development (2017). PISA 2015 Results (Volume III).Paris,Francee. (Crossref),(Google Scholar)

[20] Republic of Kenya Ministry of Education (2019). Basic education statistical booklet. Retrieved https://www.education.go.ke/images/approved_Basic_Education_ Statistical_booklet_2019_approved_compressed.pdf
[21] Shields, P.M., \& Rangarajan, N. (2013). A playbook for research methods: Integrating conceptual frameworks and project management. Chapter on descriptive research (4). pp. 109-158. Retrieved from https://store.newforums.com/A-Playbool-forResearch-Methods-SEB005.htm

[22] Shiundu,A.(2019).Dissatisfaction with free public education. Deutsch. Retrieved from https://www.dandc.eu/en/article/kenyaeven-poor-parents-send-their-kids-private-schools

[23] Taherdoost,H.(2016). Sampling methods in research methodology; How to choose a sampling technique for research. SSRN Electronic Journal 5(2);18-27. Dol:10.2139/ssrn.3205035. Retrieved from https://www.researchgate.net/publication/319998246

[24] Venkatachalam,J. \& Chellamuthu,S. (2019). Sources of academic stress among higher secondary school students;337730389. Retrieved from http://www.researchgate.net

[25] Wanjiku,J.K., Omighodun,O.O., Bella,T.A., \& Adedokun,B.(2017). Who seeks child and adolescent mental health care in Kenya? A descriptive clinic profile at a tertiary referral facility. Child and Adolescent Psychiatry and Mental Health Journal 11 (1), 14, 2017

[26] World Health Organization (2020). Adolescent and mental health. Retrieved from https://www.who.int/news-room/factsheets/detail/adolescent-mental-health 